\title{
Investigation on Operating Parameters of the Homemade Penning-Type Ion Source for Cyclotron
}

\author{
Silakhuddin ${ }^{*}$ and S. Santosa \\ Center for Accelerator Science and Technology, National Nuclear Energy Agency \\ Jl. Babarsari, Yogyakarta 55281, Indonesia
}

\section{ARTICLE INFO}

Article history:

Received 04 October 2014

Received in revised form 28 April 2015

Accepted 05 May 2015

\section{Keywords:}

Ion source

Cyclotron

Parameters

Puller voltage

Magnetic field

Cathode current

\begin{abstract}
A B S T R A C T
A Penning-type ion source for a cyclotron producing PET radioisotopes has been made. To determine the performance of the ion source for further developments, an investigation on the operating parameters has been conducted. The investigation was carried out by experiments on an ion source test device. The investigated operating parameters were the puller voltage, the magnetic field, the hydrogen gas flow rate, and the cathode current. The results showed that the puller voltage was the most sensitive parameter to change ion beam current, and at a voltage of $8 \mathrm{kV}$ an ion beam current of $35 \mu \mathrm{A}$ was obtained. The puller voltage is still likely to be raised if the current beam is to be increased. Increasing the magnetic field beyond approximately 450 gauss caused the ion beam to saturate. It was obtained that a moderate range of gas flow rate on the value of $5-10 \mathrm{cc} / \mathrm{min}$, producing a high beam current with no significant effect to decrease a vacuum level. Cathode current magnitudes of up to $1 \mathrm{~mA}$ significantly affect the beam current, while above this value the beam current tends to be constant.
\end{abstract}

\section{INTRODUCTION}

Development activities to build a cyclotron are currently being conducted in the Center for Accelerator Science and Technology BATAN, and one of the activities is the development of a Penning-type ion source. Currently, an ion source development is already at the end stage of the experimental phase, and will continue with the construction phase to create an ion source to be installed at the cyclotron. A recent testing of the ion source resulted in an $\mathrm{H}^{-}$ion beam current of $35 \mu \mathrm{A}$. The test was performed on a homemade ion source testing device with a puller voltage of $8 \mathrm{kV}$ DC.

A similar ion source was tested at the Institute of Fluid Physics, China Academy of Engineering Physics, with the result that the ion beam current was $200 \mu \mathrm{A}$ at a puller voltage of $2 \mathrm{kV}$ [1]. In the

\footnotetext{
*Corresponding author

E-mail address: silakh@batan.go.id

DOI: http://dx.doi.org/10.17146/aij.2015.414
}

test, only the effects of the operating parameters on the characteristics of gas discharge in the ionization chamber were observed, and the report does not directly mention the parameters' effects on ion beam current. Another test in Sungkyunkwan University, Korea, obtained an $\mathrm{H}^{-}$ion beam current of $1 \mathrm{~mA}$ at a puller voltage of $1 \mathrm{kV}$ [2]. Here there is no mention of how the characteristics of the extracted ion beam current was affected by changes in the operating parameters. Nevertheless, if compared to the results of those experiments in terms of the magnitude of the ion beam current, the homemade ion source has not attained a standard performance. It is important to investigate the characteristics of the operating parameters in order to arrive at methods to increase the ion source's performance.

The $\mathrm{H}^{-}$ion production in a Penning-type ion source occurs through a non-simple process of hydrogen gas plasma formation [3]. The process is influenced by several parameters, namely cathode voltage, puller voltage, gas flow rate, and the 
intensity of the magnetic field [4]. Investigations of the ion source parameters were carried out by experiments to study the influence of the operating parameters on the end product of the ion beam current. The experiments were executed on an ion source testing device. The investigations resulted in data which will be used for further research and development of ion source design for DECY-13 cyclotron. The goal of the research and development is to obtain an $\mathrm{H}^{-}$-beam current of several hundred $\mu \mathrm{A}$.

\section{EXPERIMENTAL METHODS}

\section{The penning source and its testing device}

The scheme for the Penning ion source for cyclotron and the associated testing device is shown in Fig. 1.

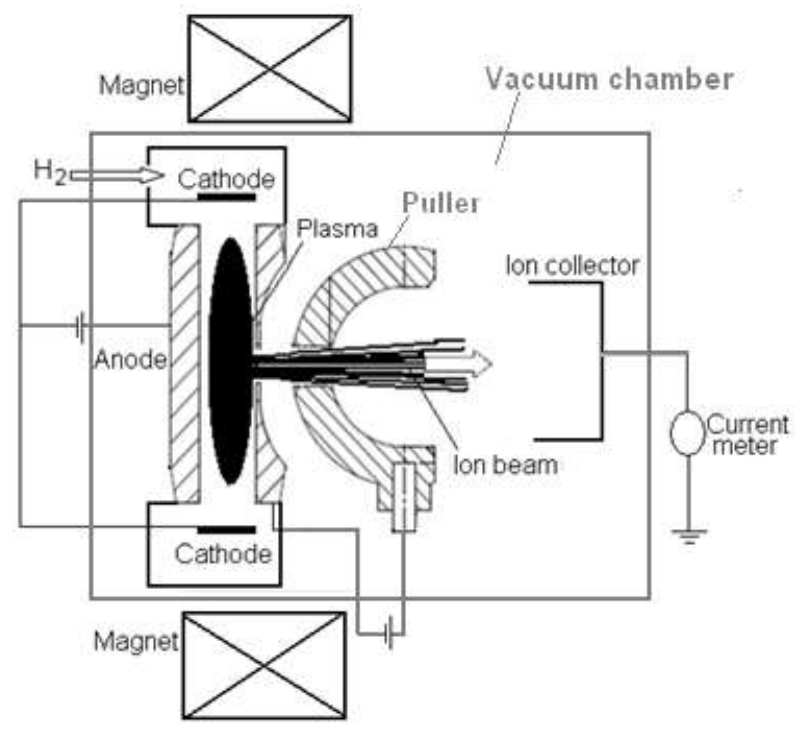

Fig. 1. Scheme of the ion source and the testing device.

Plasma is produced in the anode cavity by a hydrogen gas ionization discharge between the cathode and the anode; those are connected to a $0-3 \mathrm{kV}$ DC source. The intensity of the ionization is amplified by a magnetic field of 0-1000 gauss. Negative hydrogen ions are pulled by puller, to which $0-10 \mathrm{~V}$ DC relative to the anode is applied. The ion beams are measured by a collector and a current meter. The present geometry of the ion source, especially the surface of the anode and the puller, follow the shape of common $\mathrm{H}^{-}$ion source [1,5]. The distance between the anode aperture (slit) and the puller aperture is $0.5 \mathrm{~cm}$ and the distance between the puller aperture and collector is $3 \mathrm{~cm}$. The material of the anode is $\mathrm{W}-\mathrm{Cu}$ alloy, while the cathode material is tantalum and the puller is graphite. The magnetic field was generated by an electric current of $0-15 \mathrm{~A}$ in the winding.

\section{Experimental procedures}

The main operating parameters of ion sources are: 1) The cathode electric current, referred to as the electron current, which ionizes the gas in the anode cavity; 2) The magnetic field strength of electromagnet that affects the intensity of ionization in the anode cavity; 3 ) The hydrogen gas flow rate that affects the plasma pressure; and 4) The puller voltage that affects the extracted ion beam current from the anode cavity.

Experiments were done by first obtaining the vacuum condition at the highest level of $10^{-6}$ Torr, followed by observation of ionization in the anode cavity by the following steps: 1) Hydrogen gas was piped into the head until reaching a flow rate of several cc/minute; and 2) The cathode voltage was raised to over $1800 \mathrm{~V}$; this is the voltage that allows electrons from the tantalum cathode surface to escape toward the anode cavity [6].

Electrical current-generating magnetic field was raised to observe a glow on the anode slit, as a sign that glow discharge ionization has occurred. After ionization was observed, the next step was observing the influence of ion source operating parameters on ion beam current by the following steps: 1) Observation of the influence of puller voltage change on ion beam current; 2) Observation of the influence of magnetic field on ion beam current, and the calibration to determine the relationship between electrical current and magnetic field that was done before; 3) Observation of the influence of gas flow rate change on ion beam current; and 4) Observation of the influence of cathode current change on ion beam current.

\section{RESULTS AND DISCUSSION}

After the flow rate of hydrogen gas was raised to $2 \mathrm{cc} / \mathrm{min}$, the vacuum decreased from $5 \times 10^{-6}$ Torr to $5 \times 10^{-5}$ Torr. After cathode voltage was raised to slightly over $1800 \mathrm{~V}$ and the electromagnet current was raised to $10 \mathrm{~A}$ (based on the calibration, this value is equivalent to a magnetic field of 465 gauss), a visible glow could be observed on the anode slit. It is an indication that a plasma has arisen. The occurrence of ionization was also ensured by the cathode current of $5 \mathrm{~mA}$. After the occurrence of ionization, the observed results of the influence of the operating parameters on the ion beam current are as follows. 
The measurement data results of the influence of the puller voltage on the beam current are shown in Fig. 2.

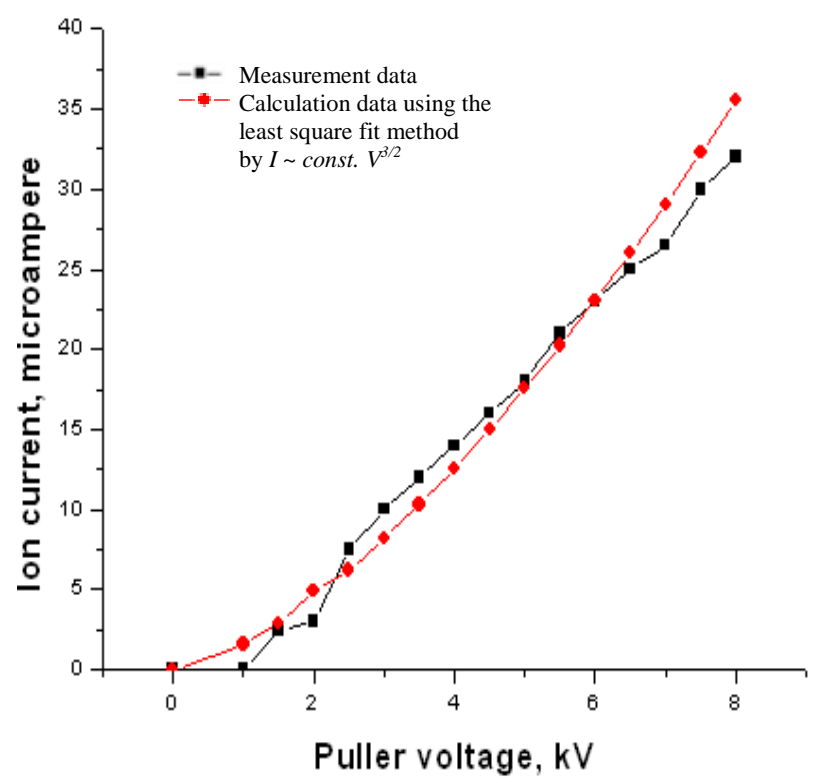

Fig. 2. The influence of the puller voltage on the ion beam current.

The data were acquired for puller voltages of up to $8 \mathrm{kV}$. Above this value, excessive spark occurred in the space between anode and puller, so the ion beam current was difficult to measure. The excessive spark was due to dropping vacuum level caused by an inadequately powerful vacuum pump. At a puller voltage of $8 \mathrm{kV}$, an ion beam current of $35 \mu \mathrm{A}$ was obtained.

Theoretically, the influence of puller voltage is expected to comply with the Child-Langmuir equation, i.e. the ion beam current is proportional to power $3 / 2$ of the extraction (puller) voltage, which is I const $\times V^{3 / 2}[7,8]$. Figure 3 shows the curves of measured and theoretically-calculated ion beam current, and two curves are seemed to coincide with each other. From these two curves, two conclusions can be drawn, namely: first, the optics of the anode-puller functions properly for extracting ion beam; and second, the space charge effect of ion beam does not affect the ion beam current.

The observation was done on the same gas flow rate as the earlier observation, but the puller voltage was reduced to $7 \mathrm{kV}$ to prevent or reduce the excessive spark. When the electric current of the electromagnet was varied, the effect of the variation of magnetic field on the ion beam current is shown in Fig. 3.

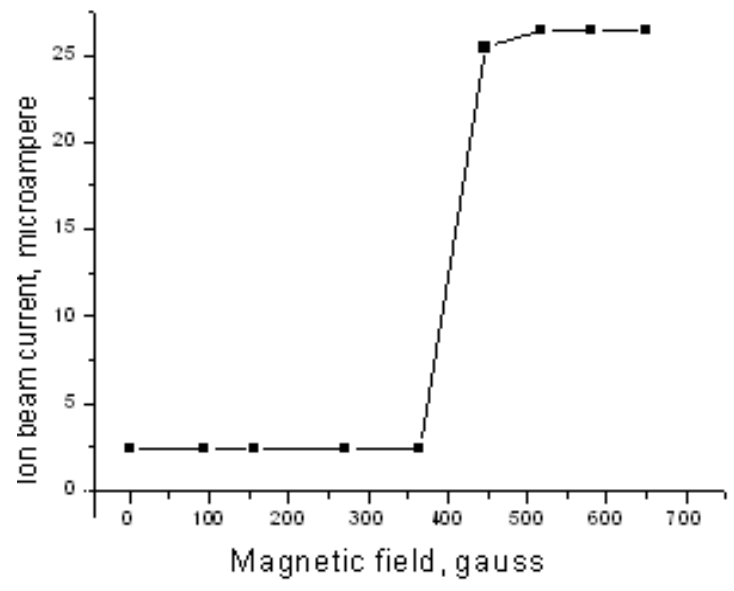

Fig. 3. Effect of magnetic field on the ion beam current.

From above results, the ion beam current appears constant even if the magnetic field is increased. Thus, it can be concluded that for magnetic fields of up to 700 gauss, the ion beam current cannot be increased by increasing the magnetic field. However, this phenomena is still to be further examined, since several references mention that the testing of this type of ion source is generally done at magnetic field strengths of several kilogauss $[1,2,9]$.

At the puller voltage of $7 \mathrm{kV}$ and electromagnet electric current of $10 \mathrm{~A}$, the influence of gas flow rate on ion beam current is shown in Fig. 4.

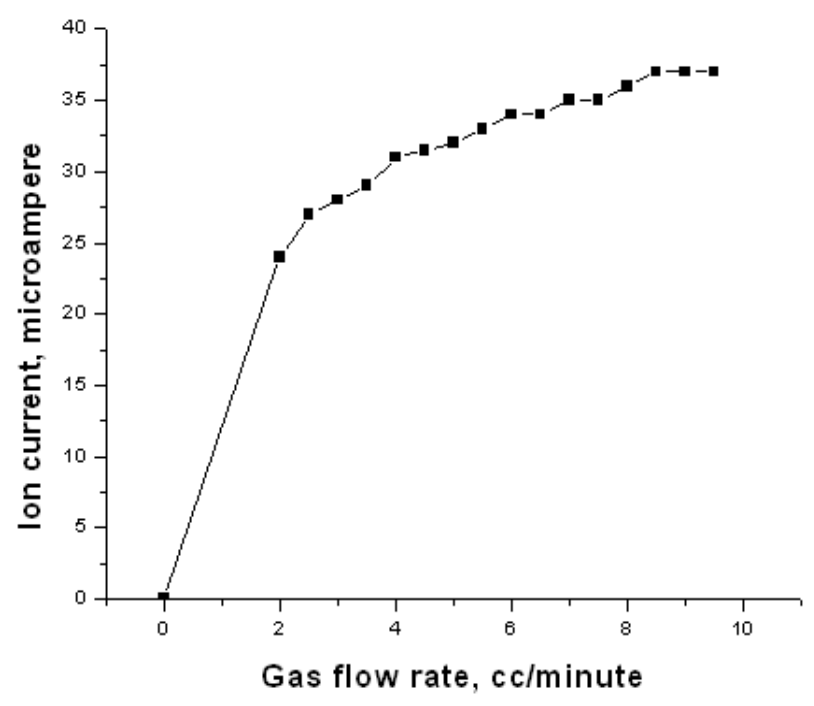

Fig. 4. Influence of gas flow rate on ion beam current at a puller voltage of $7 \mathrm{kV}$ and an electro-magnet electric current of $10 \mathrm{~A}$.

There is a minimum flow rate of value of $2 \mathrm{cc} / \mathrm{min}$ and no optimum value until $10 \mathrm{cc} / \mathrm{min}$. The ion beam current is not strongly influenced by the gas flow rate. A result of simulation study using Fluent 6 showed that gas flow rate linearly affects gas pressure in the anode cavity [10], and gas pressure linearly affects the intensity of the 
ionization [11]. The linear relation was not observed in the experiment. This may be caused by nonlinear effects of gas flow rate on the gas pressure, which occur because not all of the molecules entering the anode cavity are ionized; instead, part of them simply pass and leave the cavity as neutral molecules. Further, it was found that at a moderate range of flow rate of $5-10 \mathrm{cc} / \mathrm{min}$, a high beam current was produced, but the vacuum level did not decrease as an effect. This flow rate range corresponds to Penning-type ion source operation on cyclotron in general [12-14]. In the experiment, the cathode current rose from $6 \mathrm{~mA}$ to $10 \mathrm{~mA}$ as gas flow rate increased from $2 \mathrm{cc} / \mathrm{min}$ to $10 \mathrm{cc} / \mathrm{min}$.

The influence of cathode current on ion beam current at a gas flow rate of $2 \mathrm{cc} / \mathrm{min}$, a puller voltage of $6 \mathrm{kV}$ and an electromagnet electric current of $10.5 \mathrm{~A}$ (corresponding with a magnetic field of 465 gauss) is shown in Fig. 5.

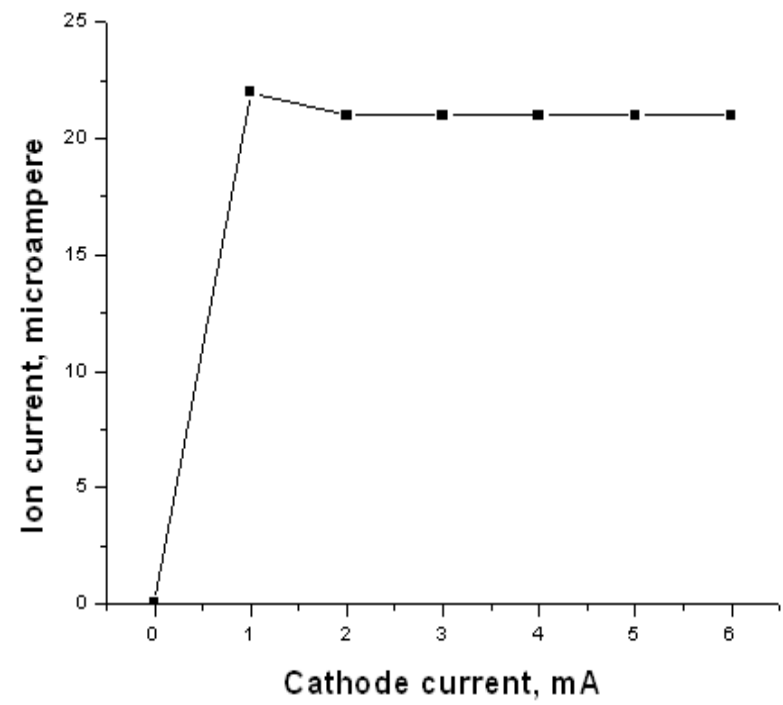

Fig. 5. The influence of the cathode current on the ion beam current.

The increase of the cathode current significantly affects ion current until $1 \mathrm{~mA}$; beyond that value, it does not affect the ion beam current. This phenomenon can occur because even though the increase of gas flow rate will increase the number of $\mathrm{H}^{-}$ions, the increase of the gas flow rate also increases the gas pressure in the extraction region; in turn, this increase in gas pressure will increase the neutralization process of $\mathrm{H}^{-}$ions. Therefore, further experiments should be conducted with cathode currents in several tens or hundreds $\mathrm{mA}$. Increasing the ion beam current to that level requires a change in the ionization from the glow discharge state to the arc discharge state, which can be done by using thermionic emission to produce electrons from the cathode surface. Technically, this can be done by increasing the cathode current up to several hundred $\mathrm{mA}[15]$.

\section{CONCLUSION}

An investigation on the operating parameters of the ion source has resulted in the data of the effect of the parameters on the ion beam current. The puller voltage has the most substantial role in affecting ion beam current, and this parameter is still likely to be raised more than $8 \mathrm{kV}$ if the current beam is to be increased. The effect of the magnetic field at several hundred gauss was to cause saturation, and it will be a next topic to be researched by increasing the magnetic field. An adequate gas flow rate was obtained to be in the range of 5 to $10 \mathrm{cc} / \mathrm{min}$. The effect of the cathode current at several $\mathrm{mA}$ was to cause saturation, and to obtain a higher ion beam current, it will be necessary to attempt to increase the cathode current to reach the arc discharge ionization mode.

\section{ACKNOWLEDGMENT}

This experiment was funded by an annual R\&D program of the Center for Accelerator Science and Technology, the National Nuclear Energy Agency of Indonesia, so the authors would like to thank the head of the center. The authors also would like to thank Mr. Sunarto for his support throughout the experiments and measurements.

\section{REFERENCES}

1. J. Long, Z. Yang, P. Dong et al., Nucl. Sci. Tech. 24 (2013) 040201.

2. Y.H. Yeon, H.S. Kim, K.M. Gad et al., Development Study of Penning Ion Source for Compact $9 \mathrm{MeV}$ Cyclotron, Proceedings of Cyclotrons (2013) 197.

3.S. Korenev, Critical Analysis of Negative Hydrogen Ion Sources for Cyclotrons, Proceedings of Cyclotron (2013) 192.

4. Wang, Z. Yang, P. Dong et al., Rev. Sci. Instrum. 83 (2012) 063302-1.

5. V. Dudnikov and R.P. Johnson, High Brightness $H$ Plasma Source, Proceedings of 1st International Particle Accelerator Conference (2010) 4224.

6. I. Jepu, C. Porosnicu, I. Mustata et al., Romanian Reports in Physics 62 (2010) 773. 
7. M.E.M. Eisa, J.L. Conradie and P.J. Cellier, World Journal of Nuclear Science and Technology 3 (2013) 85.

8. D. Faircloth, S. Lawrie, C. Gabor et al., Rev. Sci. Instrum. 83 (2012) 02A701-2.

9. Z. Yang, J.D. Long, P. Dong et al., Chinese Physics C (HEP \& NP) 36 (2012) 1001.

10. Silakhuddin, Journal of Saintek 17 (2012) 21. (in Indonesian).

11. D.M. Goebe, R.E. Wirz and I. Katz, Journal Propulsion and Power 23 (2007) 5.
12. B.C. Lee, H.J. Lee and J.H. Park, Journal of the Korean Physical Society 57 (2010) 1378.

13. Anonymous, Technical Specifications of Sumitomo HM-12S of PET Radio-Tracer Production System for RS Kanker Dharmais, Sumitomo Heavy Industries Ltd., PT Philips Indonesia, Jakarta (2008) 17.

14. Y.H. Yeon, M. Ghergherehchi, X.J. Mu et al., Nucl. Instrum. Meth. Phys. Res., $\mathbf{A 7 6 3}$ (2014) 510.

15. M.M.A. Rahman, International Journal of Instrumentation Science 1 (5) (2012) 66. 